\title{
O ROMANCE E A IDENTIDADE NARRATIVA: KUNDERA NO LABORATÓRIO DE RICOEUR
}

\author{
THE NOVEL AND THE NARRATIVE IDENTITY: KUNDERA AT RICOEUR'S LABORATORY \\ Vítor Hugo dos Reis Costa'
}

\section{RESUMO}

Trata-se de traçar uma aproximação comparativa entre dois autores oriundos de campos distintos do saber e da cultura e visualizar a mútua contribuição decorrente dessa aproximação, a saber, entre a filosofia de Paul Ricoeur (1913-2005) e o romance de Milan Kundera (1929-). Na medida em que tanto a filosofia de Ricoeur quanto a prosa ficcional de Kundera refletem sobre a constituição da subjetividade na modernidade, a presente contribuição visa estabelecer paralelos entre suas concepções de subjetividade e suas reflexões sobre os destinos da prática da narração ficcional na virada do século. Tendo isso em vista, pretendo realizar uma interpretação comparativa entre as teses de Ricoeur, especialmente apresentadas em Tempo e narrativa e $O$ si-mesmo como outro e as de Kundera, expostas tanto em seus ensaios quanto apresentadas de forma esparsa em digressões reflexivas que permeiam sua prosa romanesca. Meu intuito será mostrar como se diferenciam de forma discreta mas se sintonizam de forma robusta no que concerne a relação entre a constituição da subjetividade, o papel do romance na existência e a imersão desta em enredos historicamente considerados.

Palavras-chave: hermenêutica, Kundera, Ricoeur, romance.

\section{ABSTRACT}

It is about drawing a comparative approach between two authors from different fields of knowledge and culture and visualizing the mutual contribution resulting from this approach, namely, between the philosophy of Paul Ricoeur (1913-2005) and the novel of Milan. Kundera (1929-). As both Ricoeur's philosophy and Kundera's fictional prose reflect on the constitution of subjectivity in modernity, this contribution aims to draw parallels between his conceptions of subjectivity and his reflections on the fate of the practice of fictional narration at the turn of the century. With this in mind, I intend to do a comparative interpretation between Ricoeur's theses, especially presented in Temps et récit and Soi-meme comme un autre and those of Kundera, exposed in his essays and presented sparingly in reflective digressions that permeate his romanesque prose. My intention is to show how they are discreetly differentiated but robustly attuned about the relationship between the constitution of subjectivity, the role of the novel in existence and its immersion in historically considered plots.

Keywords: hermeneutics, Kundera, Ricoeur, novel.

1 Doutorando do PPG-Fil da UFSM. Mestre pelo mesmo PPG-Fil. Graduado (licenciatura plena) no curso de filosofia da mesma instituição. E-mail: costavhr@gmail.com 
Thaumazein, Ano IX, v. 13, n. 26, Santa Maria, p. 49-66, 2020.

"A literatura é um vasto laboratório no qual são feitos ensaios com estimativas, avaliações, juízos aprobatórios e condenatório, graças ao que a narratividade serve de propedêutica a ética."

- Paul Ricoeur

"Descobrir o que somente um romance pode descobrir é a única razão de ser de um romance. o romance que não descobre uma porção até então desconhecida da existência é imoral. o conhecimento é a única moral do romance."

- Milan Kundera

\section{INTRODUÇÃO}

A literatura e a filosofia revelaram, no decorrer paralelo de suas histórias específicas, uma possibilidade permanente de interface. Não foram poucos os romancistas que compuseram obras que serviram, pelas mais diferentes razões, de inspiração para o pensamento filosófico. Por outro lado, não foram poucos os pensadores que, mais do que procurar inspiração na arte romanesca, realizaram suas incursões no universo romanesco através da produção de obras de ficção. Na contemporaneidade, os franceses Jean-Paul Sartre, Simone de Beauvoir e Albert Camus são, talvez, três das figuras mais exemplares dessas interfaces possíveis: escrevendo não apenas textos teóricos e ensaios filosóficos, expressaram suas ideias em textos romanescos de difícil tipologia na medida em que se tornaram textos consagrados por razões simultaneamente artísticas e filosóficas.

No presente texto pretendo aproximar as ideias de dois autores que se inscrevem nessa área de intersecção entre filosofia e literatura de modo distinto. Paul Ricoeur (1913 - 2005) e Milan Kundera (1929-) pensaram, em registros distintos mas parecidos, as relações entre o romance e a existência humana. O primeiro, filósofo por vocação, deixa entrever na tessitura de sua obra o impacto e a influência que a arte romanesca e a tradição literária lhe causaram quando, por exemplo, apresenta uma concepção narrativa de identidade pessoal e afirma que a literatura é um laboratório existencial que serve como propedêutica para a reflexão filosófica sobre ética e moral. O segundo, consagrado na história do romance e refratário à ideia de que o romance deva servir como mera ilustração de ideias, construiu ao longo das últimas décadas uma obra romanesca elogiada sobretudo por sua inteligência teórica e estética. Em um primeiro momento nossa incursão se fará na concepção da arte romanesca de cada um dos pensadores, em especial no que tange aos limites do romance e, nesse sentido, em sobre como esse modo do discurso interessou a ambos. Em seguida, tentaremos mostrar como em certo sentido é possível aproximá-los enquanto pensadores que têm uma escuta atenta para o romance enquanto galeria de narrativas exemplares cujos ensinamentos reverberam em nível ético, moral, existencial.

\section{A MISSÃO ONTOLÓGICA DE UMA PROSA FENOMENOLÓGICA}

Em O Si-Mesmo Como um Outro, Paul Ricoeur diz que a literatura é um laboratório de experimentação de possibilidades do pensamento moral (2014, p. 114). Criando o que poderíamos chamar de um "observatório ficcional" do campo prático e colocando em operação nossos esquemas e elementos de 
reflexão ética, a literatura pode oferecer um reservatório sapiencial e oferecer elementos ao imaginário moral onde a própria existência se dá.

Contudo, essa concepção da literatura não instrumentaliza a arte? Isto é, não faz com que ela seja destituída de uma finalidade que lhe seja intrínseca? Embora não pareça jamais afirmar que o sentido e a finalidade da literatura seja servir apenas e estritamente como antecâmara da reflexão moral propriamente filosófica, Ricoeur se serve vastamente da arte romanesca com finalidades eminentemente filosóficas. Seja explorando a configuração narrativa do tempo em obras de romancistas como Thomas Mann, Virginia Woolf ou Marcel Proust, seja mostrando como a constituição narrativa da identidade pessoal esbarra em seus limites com Robert Musil, Ricoeur recorre à tradição romanesca para elaborar ou resolver questões que parecem encontrar sua arena apropriada na reflexão filosófica.

Para fins de início da reflexão subsequente, abro a argumentação com uma passagem em que Ricoeur, em tom interrogativo, sugere uma significativa singularidade do romance enquanto narrativa de ficção.

O romance constitui simplesmente um entre outros gêneros da narrativa de ficção? (...) Ora, temos razões para duvidar que o romance se deixe enquadrar numa taxionomia homogênea dos gêneros narrativos. Acaso o romance não é um gênero antigênero, que justamente por isso torna impossível reunir o modo diegético e o modo dramático sob o termo englobante de narrativa de ficção? (RICOEUR, 2010b, 269)

O romance enquanto gênero parece se caracterizar, para Ricoeur, como legítimo antigênero. Tudo se passa como se o romance, na aurora de seus dias, ao descer das estratosferas do épico para o nível do prosaico e do cotidiano, tenha descoberto a possibilidade de aceder a tantas singularidades quantas fosse possível imaginar mas que também descobriu a alegre possibilidade de configurar a narração de diferentes formas. Dizendo de outro modo, a descida do épico ao prosaico constituiu uma verdadeira festa na ordem das possibilidades humanas da narração:

O romance nasceu da destruição dessa distância épica. E foi principalmente sob a pressão do riso, do ridículo, do 'carnavalesco' e, mais geralmente, das expressões do cômico sério - culminando na obra de Rabelais (...) que a distância épica cedeu lugar à contemporaneidade fundada no compartilhamento do mesmo universo ideológico e linguístico que caracteriza a relação entre o escritor, seus personagens e seu público na era do romance. Em resumo, é o fim dessa distância épica que opõe decididamente a literatura 'baixa' a todo o resto da literatura 'elevada'. (RICOEUR, 2010b, 269-270)

Para Ricoeur, "a evolução da literatura não se limita a fazer aparecer novos tipos nos antigos gêneros e novos gêneros na constelação das formas literárias. Sua aventura parece levá-la a romper o próprio limite dos gêneros e a contestar o próprio princípio da ordem que é a raiz da ideia de intriga" (RICOEUR, 2010b, p. 11). Lembrando que a "a composição da intriga foi definida, no plano mais formal, como um dinamismo integrador que tira uma história una e completa de uma diversidade de incidentes, ou seja, transforma essa diversidade em uma história una e completa" (RICOEUR, 2010b, p. 12), o romance parece o (anti)gênero por excelência para a mais adequada captação da existência individual. 
Explorar a fronteira entre as considerações filosóficas de Ricoeur para as reflexões realizadas por Milan Kundera em seus ensaios é uma possibilidade que venho explorando mas que não inaugurei². Cabe mencionar que, em língua portuguesa, prestigiados especialistas na obra de Ricoeur como Hélio Salles Gentil (2016) tem reconhecido a pertinência de uma aproximação entre a hermenêutica e os ensaios críticos de Kundera. A voz filosófica do narrador kunderiano foi, como outros aspectos filosoficamente relevantes da obra do romancista, muito bem percebida por Wilton Barroso-Filho (2008) que, se em razão de seu lamentável falecimento recente já não nos brinda com sua presença, deixou atrás de si não só uma obra em termos de escritos, palestras e orientações de trabalhos sobre as relações de Kundera com a filosofia e as contribuições do romancista tcheco para a concepção das bases de uma epistemologia do romance. Para além das pesquisas em língua portuguesa, chama atenção a similitude notada por Jean Greisch entre a sabedoria romanesca concebida por Kundera e a sabedoria prática estimada por Ricoeur. Levando talvez ainda mais elementos em consideração, há o breve, recente e excelente artigo de F. Wawan Setyadi (2019), no qual a noção de personagem de Kundera é pensada em profunda conexão com a tripla mímesis de Tempo e narrativa. Segundo Setyadi, pensar simultaneamente com Ricoeur e Kundera incrementa significativamente não só nossa compreensão das relações entre ficção e identidade pessoal no plano da narração como, no fundo, se compreende por que os seres humanos permanecem interessados em ler e escrever histórias - prática cujo desaparecimento, conforme tentarei mostrar, preocupa igualmente o filósofo e o romancista.

Se há tanto potencial de diálogo e estabelecimento de fecundos comércios entre filosofia e literatura isso não significa, em absoluto, que filosofia e literatura sejam idênticas ou a mesma coisa em algum sentido. Trata-se justamente do contrário: para que haja esse diálogo e esse comércio é preciso que, mesmo nebulosos, os limites entre a filosofia e a literatura existam. Para Kundera, a arte do romance é qualquer coisa como uma arte insubstituível, autônoma, com uma vocação única e que, além de tudo isso, em certo sentido realizaria melhor uma tarefa que a filosofia não raramente assumiu, a saber, explorar as possibilidades da existência humana em seu nível mais concreto, mais prosaico, mais cotidiano. Essa convicção já pode ser vista em seu ensaio intitulado A herança depreciada de Cervantes, presente em seu A arte do romance: "descobrir o que somente um romance pode descobrir é a única razão de ser de um romance. O romance que não descobre uma porção até então desconhecida da existência é imoral. O conhecimento é a única moral do romance" (KUNDERA, 1988, p. 11).

O que, porém, só um romance pode descobrir? E, especialmente, o que o romance pode descobrir que a filosofia não pode descobrir? Não há mesmo já no pensamento filosófico de Ricoeur uma demanda por uma modalidade de discurso que apela por narração - certamente não uma narração restrita ao registro romanesco - que elucide um campo que o pensamento por excelência conceitual simplesmente não tem condições de penetrar? Para ampliar a provocação, não recorreram ao âmbito narrativo - diário, biografia, romance - pensadores cuja preocupação era justamente jogar luzes sobre o campo concreto da existência onde o drama da vida singularmente considerada se dá? Parece-nos necessário aceitar tais provocações para articular a contribuição que a reflexão e a prática de Kundera na esfera do romance pode oferecer ao pensamento filosófico. Antes, porém, faz-se mister demarcar a recusa que o próprio Kundera manifestou em uma série de ocasiões relativamente a ideia de que o romance deva servir como

2 Em uma perspectiva distinta e com objetivos diferentes, explorei outras interfaces das relações possíveis entre as reflexões de Ricoeur e Kundera em O romance como expediente hermenêutico: sobre a singularidade do existente humano (cf. COSTA, 2020c). 
instrumento do pensamento teórico. Para visualizar isso, observemos como ele manifestou essa recusa em algumas dessas ocasiões.

Comecemos com o ataque que Kundera faz à prática romanesca de um dos filósofos que mais gozava de prestígio nos anos que antecederam a publicação das primeiras obras do romancista tcheco. Jean-Paul Sartre, para Kundera, é um autor que pode ser admirado pela sua inteligência, certamente, mas não por seus romances: para Kundera, a prosa romanesca de Sartre se assemelha à uma aula montada em forma de romance para alunos que adormeceram durante a exposição teórica (2009, p. 270). Além de, do ponto de vista da divulgação e da circulação, eclipsar uma obra com a mesma mensagem que A náusea mas que o faria de modo muito mais fiel à vocação romanesca - a saber, Ferdydurke de Wiltord Gombrowicz - Sartre apresenta de forma exagerada e dramática a tese da falta de sentido da existência, tese apresentada pelo autor polonês de forma muito mais leve, divertida e, nesse sentido, fiel à herança de Rabelais e Cervantes ${ }^{3}$.

A antipatia pela teoria filosófica como prática soberana de desvelamento de possibilidades humanas não é, contudo, restrita a este ou aquele pensador filosófico em específico. Em entrevista à Christian Salmon, Kundera expõe elementos de sua estética e Salmon lhe pergunta se não seria o caso de aceitar ao menos um adjetivo que vincularia sua estética, em certo sentido, com a filosofia em termos de uma escola específica: sua estética seria "fenomenológica". A resposta de Kundera é emblemática:

O adjetivo não é mau, mas proíbo-me de usá-lo. Tenho medo demais dos professores para
quem a arte não é senão um derivado das correntes filosóficas e teóricas. O romance conhece
o inconsciente antes de Freud, a luta de classes antes de Marx, ele pratica a fenomenologia
antes dos fenomenólogos. Que soberbas descrições 'fenomenológicas' em Proust que não co-
nheceu nenhum fenomenólogo! (KUNDERA, 1988, p. 34)

Embora refratário a essas tipificações, Kundera, porém, eventualmente deixou escapar em algumas de suas reflexões ao menos alguns elementos que permitiriam que lhe atribuíssemos alguma familiaridade com os filósofos.

A prosa não é apenas uma forma de discurso distinta do verso, mas também uma face da realidade, sua face cotidiana, concreta, momentânea e localizada no lado oposto do mito. (...) Se o romance é uma arte e não apenas um 'gênero literário' é porque a descoberta da prosa é sua missão ontológica, que nenhuma outra arte pode assumir plenamente. (KUNDERA, 2009, p. 145) ${ }^{4}$

3 Kundera sugere em diversos momentos de suas reflexões ensaísticas sobre a arte do romance que esta nasceu como o "eco do riso de deus" e, assim, vê em Rabelais um dos desbravadores desse território discursivo. Sobre o riso que Rabelais inaugura com sua prosa, diz George Minois: "Com Rabelais, começa de fato o riso moderno, que não é mais cômico. Esse riso que, como diz Octavio Paz, é 'a embriaguez da relatividade das coisas humanas, o estranho prazer da certeza de que não há certezas'. Esse riso humanista é profundamente ambíguo. Mais além da bufonaria de superfície, Rabelais prenuncia a era do absurdo, a nossa, e se ele toma o partido de rir dela é porque não adianta nada chorar por ela. É a marca de todos os ridentes sérios dos tempos modernos. É também o que, desde o século XVI, atrai para ele o ódio dos donos da verdade, que acreditam que seu sorriso é um sopro que fissura os ídolos, abala os templos de todas as religiões, verdadeiras e falsas, clericais e laicas." (MINOIS, 2003, p. 274) 4 [La prosa no es tan sólo una forma de discurso distinta del verso, sino también una cara de la realidad, su cara cotidiana, concreta, momentánea, y situada em el lado opuesto del mito. (...) Si la novela es un arte y no sólo un 'género literario' es porque el descubrimiento de la prosa es su misión ontológica, que ningún otro arte puede asumir enteramente. (KUNDERA, 2009, p. 145)] 
A prosa penetra, portanto, o prosaico, o cotidiano, isto é, a arena na qual se mostram as estruturas existenciais tão caras aos filósofos. A prosa romanesca tem, portanto, como o próprio autor sugere, uma missão "ontológica" que parece não precisar do auxílio do filosofar. Kundera, em certo sentido, ofereceria não um interdito ao afã de Ricoeur, mas uma espécie de advertência: o pensamento filosófico se põe a operar de modo fútil se pretende se servir do romance como matéria-prima de suas reflexões estas sim legítimas porque teóricas. Kundera entende que a própria arte do romance pensa e se coloca a pensar de um modo próprio, específico, independente e distinto da teoria filosófica que, segundo o romancista tcheco, tem vícios incontornáveis e que tornam seu convívio impossível com a narração e com a meditação tal como estas se dão dentro da prosa romanesca:

Um tratado filosófico que expõe um sistema está condenado a conter passagens soltas; não porque o filósofo não tenha talento, mas porque a forma de um tratado assim exige; já que, antes de chegar a suas conclusões inovadoras, o filósofo é obrigado a explicar o que os outros dizem sobre o problema, forçado a refutá-los, a propor outras soluções, escolher a melhor, argumentar a seu favor, tratando do mesmo modo o argumento surpreendente e aquele que é dado como certo, etc., de tal maneira que o leitor tem o desejo de saltar páginas para chegar no meio do assunto, ao pensamento original do filósofo. (KUNDERA, 2009, p. 165) $)^{5}$

Os romancistas preferidos de Kundera são pensadores romanescos, mas que pensam dentro de uma linguagem e uma estética própria a arte do romance. Kafka, Musil, Broch e Gombrowicz são citados pelo autor como autores que souberam introduzir a inteligência de um modo apropriado e compatível com a modalidade romanesca do discurso (2006, p. 50). Em outra ocasião, Kundera divide autores que são escritores - isto é, que sacrificam a prosa às ideias e teorias - e romancistas - perseguidores obsessivos de uma forma estética. "Rousseau, Goethe, Chateaubriand, Gide, Malraux, Camus e Montherland" (1988, p. 129) são escritores enquanto "Fielding, Sterne, Flaubert, Proust, Faulkner, Céline, Calvino" (p. 130) seriam propriamente romancistas".

Como seria então essa reflexão genuinamente romanesca? Seguindo a linha de raciocínio que faz Kundera preferir Gombrowicz a Sartre, vemos o autor fazer a defesa de seus valores estéticos:

A reflexão romanesca, tal como Broch e Musil a introduziram na estética do romance moderno, não tem nada a ver com a de um cientista ou filósofo, eu diria mesmo que ela é intencionalmente

\footnotetext{
5 [Un tratado filosófico que expone un sistema está condenado a contener pasajes flojos; no porque le falte talento al filósofo, sino porque así lo exige la forma de un tratado; ya que, antes de llegar a sus conclusiones innovadoras, el filósofo se ve obligado a explicar lo que los demás dicen del problema, obligado a refutarles, a proponer otras soluciones, elegir la mejor, alegar argumentos em su favor, el argumento que sorprende codeándose con el que se da por supuesto, etc., de tal manera que al lector le entran ganas de salta páginas para llegar por en al meollo de la cuestión, al pensamiento original del filósofo. (KUNDERA, 2009, p. 165)] 6 Desenvolvi em outra direção essas categorias classificatórias de Kundera em artigo recente no qual analiso o final do romance $O$ estrangeiro de Albert Camus. No referido texto, confronto o romance de Camus não só com as categorias classificatórias de Kundera - segundo as quais Camus seria um escritor mas não um romancista - como também com as de René Girard, apresentadas em Mentira romântica e verdade romanesca. Para este autor, a literatura existencialista de Sartre e Camus não é romanesca na medida em que não revela a estrutura triangular do desejo na qual paira, sobre o sujeito do desejo e seu objeto, a influência de um modelo mediador desde o qual o desejo será imitado. Tentei mostrar como a conclusão de $O$ estrangeiro, adequadamente interpretada, pode oferecer outra imagem da subjetividade de Meursault. (ver COSTA, 2020).
} 
Thaumazein, Ano IX, v. 13, n. 26, Santa Maria, p. 49-66, 2020.

afilosófica, até anti-filosófica, isto é, violentamente independente de todo sistema de ideias preconcebidas; ela não julga, não proclama verdades, ela se pergunta, se espanta, ela sonda; sua forma é das mais diversas: metafórica, irônica, hipotética, hiperbólica, aforística, engraçada, provocadora, fantasista; e sobretudo: ela não deixa nunca o círculo mágico da vida dos personagens; é a vida dos personagens que a alimenta e justifica. (KUNDERA, 2006, p. 69)

Em suma, até aqui, temos um pequeno panorama de um praticante da prosa romanesca demarcando de maneira ferrenha, até mesmo feroz, a distância que sua prática estabelece diante daquilo que os pensadores filosóficos entendem que seja possível fazer no que diz respeito às relações entre narração - especificamente romanesca - e reflexão teórica. Não acabamos assim estabelecendo mais fronteiras do que pontes possíveis entre o pensamento do filósofo francês e a prática romanesca e meditativa do romancista tcheco? Penso que não e que, pelo contrário, a aproximação entre certas ideias de um e de outro sobre certos assuntos específicos permitirão que visualizemos o quanto Ricoeur e Kundera participam de uma espécie de imaginário comum. Examinaremos, a seguir, a problemática da identidade pessoal na qual se colocam de modo ainda mais expressivo em contato as ideias de Kundera e Ricoeur.

\section{CARÁTER E PROMESSA, ADIÇÃO E SUBTRAÇÃO}

No prefácio de O si-mesmo como outro - obra toda inteira construída sobre uma aporia sinalizada como resultado da reflexão de Tempo e narrativa, a saber, a questão da identidade narrativa - Ricoeur demarca os limites da problemática da identidade pessoal herdada pela reflexão moderna tal como se deu desde Descartes até Nietzsche, apontando os dois autores como dois exemplares de atitudes diametralmente opostas no que tange a compreensão da subjetividade humana. Segundo Ricoeur, a subjetividade humana é exaltada em Descartes para, dois séculos depois, ser estilhaçada pela concepção nietzscheana de subjetividade fragmentada. Sem pretender que a chave de análise seja a única nem a melhor possível acerca dos posicionamentos possíveis relativamente ao tema, entendemos sua fecundidade e é com ela que pretendemos analisar algumas ideias de Kundera sobre este assunto7.

No entendimento de Ricoeur, duas figuras da identidade pessoal precisam ser concebidas para que a questão possa ser minimamente colocada de modo adequado - e o eclipse, historicamente evidenciado, de uma dessas figuras pode ser apontado como a razão de algumas aporias acerca da problemática. Essas duas figuras são a da mesmidade e a da ipseidade, e o eclipse da segunda pela primeira é uma constante que pode ser observada de modo privilegiado no pensamento de Descartes e no de Nietzsche.

\footnotetext{
7 Os mesmos Descartes e Nietzsche são frequentemente lembrados quando o tema é a questão da subjetividade. As ideias de Sartre em A Transcendência do Ego, por exemplo, aproximam Descartes de Freud no que diz respeito às suas concepções substanciais de subjetividade - exaltação da consciência e, depois, do inconsciente em detrimento da consciência - indo de encontro àquelas formalistas de Kant e Husserl que concebem a subjetividade transcendental como sendo o âmbito mais fundamental da subjetividade (cf. SARTRE, 2013, p. 15s). Maclntyre, por outro lado, em Depois da virtude, transforma Nietzsche em uma espécie de observatório no qual todas as consequências reprimidas e indesejadas pelo pensamento moderno vieram à tona, revelando o fundo irracional e pulsional do pensamento que, no contexto da preocupação de MacIntyre com a reflexão moral, sempre fora disfarçada e mascarada nas teorias que o precederam (cf. MACINTYRE, 2001, p. 189-208).
} 
Thaumazein, Ano IX, v. 13, n. 26, Santa Maria, p. 49-66, 2020.

A singularidade estaria habilitada a partir de uma dupla função: a identidade-idem, que indica a permanência no tempo, e a identidade-ipse, que implica na mudança. Assim, a própria estrutura do singular em Ricoeur carrega consigo a herança de uma quase-essência, sob a categoria de identidade-idem; de outro, se abre para o fluxo contínuo da existência pela categoria de identidade-ipse. (ROSSATTO, 2013, 165)

O que pode haver em comum, porém, entre duas perspectivas aparentemente tão distintas quanto Descartes e Nietzsche? O primeiro, pai do racionalismo filosófico, concebe a subjetividade nucleada em uma substância pensante que será reformulada e reconfigurada nas filosofias transcendentais e idealistas por toda a modernidade (RICOEUR, 2014, p. XVI) enquanto o outro é justamente o polo irracionalista da mesma modernidade, explorador de seus limites e autor de uma obra que traz à tona uma série de pressupostos inconfessados da reflexão propriamente moderna. O que os une, porém, é a mesma dúvida metafísica, que Nietzsche radicaliza - duvidando do próprio Cogito e mesmo da possibilidade da verdade -, mas não supera ao permanecer no interior da pergunta o que?, que não permite que a subjetividade apareça senão eclipsada e dissolvida na universalidade do conceito.

Já em Tempo e narrativa, Ricoeur sinalizava para a necessidade da formulação da pergunta pelo quem?, esta sim capaz de apontar para o âmbito singular da identidade pessoal. Mencionando a elaboração de Hannah Arendt da mesma questão (2010, p. 418), Ricoeur aponta que a questão da ipseidade do sujeito só aparece quando a história da vida é contada, isto é, o "quem" da ação é inapreensível conceitualmente e não pode ser adequadamente apresentado por mera listagem de qualidades, demandando narração capaz de singularizar o sujeito que, nesses termos, é pensado em termos próximos aos de um personagem.

Em Tempo e narrativa Ricoeur sugere que o dilema entre as concepções substancialistas e suas negações humeana e nietzscheana "desaparece se a identidade entendida no sentido de um mesmo (idem) for substituída pela identidade entendida no sentido de um si-mesmo (ipse)" (2010, p. 418-419). Sua oposição muda, porém, em 0 si-mesmo como outro e aponta para a necessidade de um comércio entre o polo da ipseidade e da mesmidade, não pretendendo mais a substituição desta por aquela, mas afirmando que:

A identidade narrativa fica de permeio; ao narrativizar o caráter, a narrativa lhe devolve o movimento abolido nas disposições adquiritas, nas identificações-com sedimentadas. (...) A identidade narrativa mantém unidas as duas pontas da cadeia: a permanência do caráter no tempo e a permanência da manutenção de si. (RICOEUR, 2014, p. 178)

Ou seja: o dilema moderno que conduz a problemática da subjetividade e da identidade narrativa às aporias que lhe são intrínsecas se dá em função do eclipse da função narrativa que traz à tona a constituição do caráter na unidade de uma história. Também convém notar que além de ser entendida como uma categoria da prática (2010, p. 418) e que não está isenta nem de falhas nem de possibilidades de agenciamentos configurativos antagônicos dos mesmos elementos (2010, p. 422) a identidade narrativa se faz pertinente como conceito que transborda os limites - e ao mesmo tempo os rearticula sob o signo de categoria polivalente - da historiografia, da ficção e da ética. É por essa razão que o intercâmbio entre essas disciplinas é possível e, para meu interesse presente, é por essa 
razão que nos permitimos afirmar que a meditação sobre o romance pode trazer ensinamentos éticos e ontológicos. Com esses elementos em mente, passo a consideração acerca da noção de subjetividade que subjaz a prosa romanesca de Kundera.

Em A imortalidade, Milan Kundera nos oferece um romance que, na opinião de Merrill (2016), é sua obra de maior valor estético. Realizando uma polifonia de vozes que já se observava em $O$ livro do riso e do esquecimento e em A insustentável leveza do ser, Kundera combina a narração ficcional com sua prosa meditativa. Vamos nos concentrar na história das personagens Agnes e Laura. Primeiro, porém, cabe mencionar que a constituição das identidades das personagens é inseparável da estética da composição do próprio romance.

Agnes e Laura são apresentadas mediante um estilo narrativo bastante singular e protagonizam um romance que pode ser o momento de maior acabamento estético de toda a obra de Kundera. Em vez de narrar as histórias de Agnes e Laura de maneira linear, Kundera nos oferece cenas das vidas das irmãs na esteira de uma longa prosa meditativa que pode mesmo ser considerada a voz majoritária que compõe o romance ${ }^{8}$. Refletindo sobre certos temas que vão de um arco mais existencial e estrutural da condição humana até a consideração de elementos históricos que configuram os cenários das escoIhas que as personagens fazem, Kundera nos apresenta Agnes e Laura, portanto, sempre situadas em cenários tematicamente constituídos. Sem tentar acompanhar seus pensamentos com um microfone joyceano que ele próprio confessa que não saberia usar (1988, p. 31), Kundera se torna uma espécie de comentador existencial das próprias personagens. Tal estética da composição, por si mesma, já mereceria um exame detido sob as lentes da teoria ricoeuriana. O que realizaremos, porém, é um pouco distinto: na medida em que Kundera, em sua meditação romanesca, oferece elementos para concepção da problemática da identidade pessoal - isto é, mesclando a prosa meditativa com verdadeiros ensaios reflexivos - é possível visualizar como as histórias de Agnes e Laura servem ao estilo e a estética de Kundera. Em um capítulo intitulado $A$ adição e a subtração da terceira parte de $A$ imortalidade, a prosa meditativa de Kundera dá lugar a meditação pura quando este nos diz:

Há dois métodos para cultivar a unicidade do eu: o método aditivo e o método subtrativo. Agnes subtrai de seu eu tudo o que é exterior e emprestado, para, desta forma, aproximar-se de sua essência pura (correndo o risco de chegar a zero com essas subtrações sucessivas). O método de Laura é exatamente inverso: para tornar seu eu mais visível, mais fácil de ser apreendido, para dar-Ihe mais consistência, ela acrescenta-lhe sem cessar novos atributos, aos quais tenta se identificar (correndo o risco de perder a essência do eu sob esses atributos adicionados). (KUNDERA, 1998, p. 102)

8 Sobre o caráter do narrador kunderiano, diz Barroso-Filho: "Nos romances (...) A insustentável leveza do ser e A imortalidade, a continuidade dramática é seguidamente interrompida, fazendo emergir uma narrativa quase que lacônica, a primeira pessoa emerge ainda mais, agora sem nenhum pudor. Mais do que refletir, a primeira pessoa filosofa, sobre o mito nietzscheano do eterno retorno, sobre o peso e a leveza em Parmênides, sobre o materialismo de Epicuro, sobre a merda, etc... Em A imortalidade o autor filosofa sobre o significado da liberdade moderna, 'Aquela que nos permite fazermos as mesmas coisas nas mesmas horas', ou ainda conta como a personagem Agnes vai morrer e confessa ter se inspirado em um fato real lido em um jornal; adaptando o fato, o faz aparecer, um pouco depois, como o acidente que mata sua personagem." (BARROSO-FILHO, 2008, p. 3) 
Thaumazein, Ano IX, v. 13, n. 26, Santa Maria, p. 49-66, 2020.

Retomando uma dicotomia que já parecia em germe em A insustentável leveza do ser nos pares dos leves e fortes Tomas e Sabina e dos pesados e fracos Tereza e Franz ${ }^{9}$, Kundera nos apresenta personagens cuja finalidade é a de explorar situações humanas e conceitos. Curiosamente, embora Kundera nos apresente algumas ideias sobre o método de composição por adição ${ }^{10}$, a composição por subtração não pareceu merecer a mesma exposição meditativa do autor. Porém, ao final do romance, quando já é possível afirmar que em certo sentido Agnes é a heroína do romance, uma passagem emblemática acerca da personagem nos é apresentada:

[Agnes] lembrou-se de um estranho momento (...) quando fora passear pelo campo pela última vez. Chegando perto de um rio, se estendeu na relva. Ficou muito tempo assim, imaginando sentir as águas do rio atravessando-a, levando todo seu sofrimento e toda sujeira: seu eu. Momento estranho, inesquecível: ela havia esquecido seu eu, havia perdido seu eu; e nisso residia a felicidade.

Essa lembrança fez nascer nela um pensamento vago, fugaz, e no entanto tão importante (talvez o mais importante de todos) que Agnes tentou apreendê-lo com palavras:

O que é insustentável na vida não é ser, mas sim ser seu eu. Graças a seu computador, o Criador fez entrar no mundo bilhões de eus, e suas vidas. Mas ao lado de todas essas vidas podemos imaginar um ser mis elementar que existia antes que o Criador começasse a criar, um ser sobre quem ele não exerceu, nem exerce nenhuma influência. Estendida na relva, coberta pelo canto monótono do riacho que levava seu eu, a sujeira do seu eu, Agnes participava desse ser elementar que se manifesta na voz do tempo que corre e no azul do céu; agora sabia que não há nada mais belo.

(...)

Viver, não existe nisso nenhuma felicidade. Viver: carregar pelo mundo seu eu doloroso.

Mas ser, ser é felicidade. Ser: transformar-se em fonte, bacia de pedra na qual o universo cai como uma chuva morna." (KUNDERA, 1998, p. 253)

A menção ao título de uma obra anterior não é casual: aparecendo como personagem no próprio romance, Kundera já havia nos avisado, em diálogo com outro personagem, que "estava escrevendo um romance" e tal romance deveria se chamar "a insustentável leveza do ser" e que este título deveria

9 Sobre isso, ver o último capítulo de O livro da imitação e do desejo, de Trevor Merril (2016, p. 259-266). Tratei dos mesmos personagens em perspectiva semelhante em artigo intitulado Autenticidade e alívio: Kundera além de Sartre (COSTA, 2012). 10 Sobre o método aditivo também encontramos nas páginas de A imortalidade as seguintes palavras: "O método aditivo é inteiramente agradável se acrescentamos ao eu um cachorro, uma gata, um assado de porco, o amor do oceano ou as duchas frias. As coisas tornam-se menos idílicas se decidimos acrescentar ao eu a paixão pelo comunismo, pela pátria, por Mussolini, pela Igreja Católica, pelo ateísmo, pelo fascismo ou pelo antifascismo. Nos dois casos, o método continua exatamente o mesmo: aquele que defende insistentemente a superioridade dos gatos sobre os outros animais faz, em essência, a mesma coisa que aquele que proclama Mussolini o único salvador da Itália: ele apregoa um atributo do seu eu e empenha-se totalmente para que esse atributo (um gato ou Mussolini) seja reconhecido e amado por todos que o cercam.

Esse é o estranho paradoxo de que são vítimas todos aqueles que recorrem ao método aditivo para cultivar seu eu: esforçam-se em adicionar para criar um eu inimitavelmente único, mas tornando-se ao mesmo tempo os propagandistas desses atributos adicionados, fazem tudo para que o maior número de pessoas se pareçam com eles; e então a unicidade de seu eu (tão trabalhosamente conquistada) logo desaparece." (KUNDERA, 1998, p. 103) 
pertencer ao romance que ele estava escrevendo no momento presente (1998, p. 234). Chegando à uma elaboração ainda mais nítida e clara do que quer dizer com a expressão - outrora já utilizada como expressão que nomeava a experiência que a personagem Sabina, esta sim de A insustentável leveza do ser, chegava ao solitário término de uma jornada de incontáveis traições, partidas e abandonos -, Kundera parece levar Agnes, a encarnação do método subtrativo de composição da subjetividade, até a apoteose de seu caminho, de seu estilo de vida. Repetimos: Agnes encarna um modelo de composição da subjetividade. Sua irmã Laura, porém, encarna outro que é, ironicamente, materialmente composto pelos gestos da irmã. Kundera, em frase bem percebida por Merrill (2016) como aporte que evidencia a inspiração de seu estudo que persegue a teoria do desejo mimético de René Girard evidenciado nas páginas do romancista tcheco, nos diz que "era ela [Agnes] que mostrava o caminho à sua irmã, ao mesmo tempo que o barrava." (1998, 95). Laura imita o repertório de gestos de Agnes, imita seus óculos escuros e, ao final do romance, depois da morte de Agnes, se casa com o viúvo Paulo, até então marido de Agnes. Nos termos de Ricoeur, os traços estáveis de Laura são justamente aquelas em que ela se inspirara na irmã que, na prosa de Kundera, encarna um método de cultivo da unicidade do eu que consiste, justamente, em se despir do que é inessencial - um método que, como vimos, flerta e acaba culminando com o despojamento do próprio eu.

Aqui cabe, pois, perguntar: Agnes, a heroína desse romance, não flerta com uma espécie de mesmidade negativa de cariz humeano e nietzscheano? Mais: a própria estética do romance de Kundera não é um flerte com os limites da narração que, ironicamente, permite que Laura seja um melhor exemplo de composição narrativa da identidade do que Agnes?

Agnes viaja para a Suíça para ficar sozinha, para flertar com uma solidão que a despoja do peso do próprio eu. Agnes, que é apresentada de forma narrativa pela prosa meditativa de Kundera, parece o tipo de pessoa que seria refratária à aceitação da própria identidade concebida em termos narrativos. A heroína do mais bem elaborado romance de Kundera parece não apenas encarnar uma forma de composição da subjetividade mas também os ideais estéticos que norteiam a composição de Kundera que, apresentados em muitos momentos de seus romances e ensaios, recebem uma interessante definição no corpo do próprio romance examinado quando este, enquanto personagem, confessa a um interlocutor:

Lamento que quase todos os romances escritos até hoje obedeçam demais à regra da unidade de ação. Isto é, que estejam fundamentados apenas numa sequência causal de ações e acontecimentos. Esses romances parecem uma rua estreita, ao longo da qual os personagens são perseguidos com chicotadas. A tensão dramática é a verdadeira maldição do romance, porque transforma tudo, mesmo as mais belas páginas, mesmo as cenas e as observações mais surpreendentes, numa simples etapa que leva ao desfecho final, onde se concentra o sentido de tudo que precede. Devorado pelo fogo de sua própria tensão, o romance se consome como um monte de palha. (KUNDERA, 1998, p. 234)

Atentemos: a unidade da ação é a maldição do romance ao sacrificá-lo à tensão dramática que o consome em chamas na direção de um final na qual todo o desenrolar narrativo não pode senão cumprir a função de um trajeto, nunca de um fim em si mesmo. O que vale para o romance aqui não valeria para a própria constituição da identidade narrativa? Mais: a unidade do personagem não sofreria uma 
fragilidade exatamente daquele tipo que perturba Ricoeur? Agnes não encarna o oposto da sempre provisória e frágil vitória, oportunizada pela narração, da concordância sobre a discordância? A estética de Kundera não propõe, em certo sentido, uma espécie de prática que inverte as prioridades de Ricoeur?

Ricoeur se defrontou com romances que parecem levar as tensões da narratividade aos seus limites. Em O si-mesmo como outro o filósofo francês comenta $O$ homem sem qualidades de Robert Musil - romancista que, lembremos, está na constelação-guia de Kundera - e sua consideração parece valer integralmente para o estilo da prosa de Kundera quando diz que "no caso de Robert Musil, a decomposição da forma narrativa, paralela à perda de identidade da personagem, leva a extrapolar as fronteiras da narrativa e atrai a obra literária para as proximidades do ensaio" (RICOEUR, 2014, p. 157). O que não significa que a posição de Ricoeur seja inflexível. O filósofo francês admite, por exemplo, que:

Rejeitar a cronologia é uma coisa; recusar todo princípio substitutivo de configuração é outra. É impensável que a narrativa possa dispensar toda e qualquer configuração. O tempo do romance pode romper com o tempo real: essa é a própria lei da entrada na ficção. (...) Acreditar que acabamos com o tempo da ficção porque sacudimos, desarticulamos, invertemos, atropelamos, reduplicamos as modalidades temporais às quais os paradigmas do romance 'convencional' no habituaram é acreditar que o único tempo concebível seja precisamente o tempo cronológico. É duvidar dos recursos que a ficção tem para inventar suas próprias medidas temporais, é duvidar que esses recursos possam encontrar no leitor expectativas, relativas ao tempo, infinitamente mais sutis que as relacionadas com a sucessão retilínea. (RICOEUR, 2010b, p. 43)

Ou seja: Ricoeur não rejeitaria a legitimidade de uma prosa que medita mais do que narra e na qual a narração parece subjugada diante da potência da meditação, embora talvez isso faça com que um Musil - ou um Kundera - possa ser pensado também como um ensaísta. Se em Musil é a imensa extensão da obra e as dimensões diminutas do enredo que tencionam a ipseidade contra a mesmidade, em Kundera é o próprio método de subtração que reduz ao mínimo a quantidade de qualidades duradouras que seriam matéria prima da narração identitária. A ideia de uma ipseidade pura e desamparada da mesmidade, como observa João Botton, "é somente uma hipótese especulativa com função bem determinada, a de fazer trabalhar ao limite a dialética da ipseidade e da mesmidade fazendo distinguir teoricamente ao máximo a primeira da segunda" (BOTTON, 2017, p. 124) pois "enquanto todos os traços de mesmidade se dissolvem com a dissolução da unidade da composição, a ipseidade permanece marcando o lugar vazio a ser ocupado pelo sujeito, ainda que esse lugar não possa ficar vazio por muito tempo" (p. 79).

Pensando Kundera enquanto um ensaísta que pensamos ser possível fazê-lo emergir enquanto pensador que, através do seu estilo estético, nos apresenta personagens que encarnam seus valores estéticos. Porém, Kundera confessa que as categorias estéticas sempre lhe apareceram como categorias existenciais"11. Não estará Kundera, assim, colocando a si mesmo - ou, talvez de modo mais bem dito,

11 Diz o romancista em A cortina: "Os conceitos estéticos só começaram a me interessar no momento em que percebi suas raízes existenciais, quando os compreendi como conceitos existenciais; pois no decorrer da vida, a pessoas - sejam simples ou sofisticadas, inteligentes ou tolas - são constantemente confrontadas com o belo, o feio, o sublime, o cômico, o trágico, o lírico, o dramático, a ação, as peripécias, a catarse, ou, para falar de conceitos menos filosóficos, com a agelastia, o kitsch ou o vulgar; todos esses conceitos são pistas que conduzem a diversos aspectos da existência, inacessíveis por qualquer outro meio." (KUNDERA, 2006, p. 98) 
sua prática - em um terreno aporético onde a dificuldade de classificação the torne alvo fácil diante da tipificação como ensaísta e teórico? Seus personagens abstratos parecem, eventualmente, encarnação de ideias no âmbito formal da composição em que são apresentados e no âmbito material da narrativa que, ao encarnarem, se tornam posições materialmente ilustradas das ideias do autor. A identidade de suas personagens parece perfeitamente concebível narrativamente: se Agnes é um flerte com o despojamento do eu, esse anseio de despojamento francamente apresentado na narração e na meditação de Kundera parecem enfatizar a robustez do ferramental conceitual de Ricoeur, afinal, não será Agnes a pretensa heroína de um Cogito humilhado? Se sim - e parece possível afirmar que sim - isso só demonstra a vitalidade da teoria narrativa de Ricoeur que, agenciando os traços de caráter de Laura ou o desejo de despojamento de Agnes mostra como a tessitura narrativa da identidade é mais dinâmica do que o mero ato ou desejo de afirmação (adição) ou negação (subtração) de traços. Conforme a possibilidade aberta no célebre artigo Against narrativity, de Galen Strawson (2004), é preciso admitir que nem todos os seres humanos têm a possibilidade ou eventualmente o interesse em se identificar com histórias. Considerando tais personalidades sob o conceito de "episódicas", Strawson usa uma palavra-chave que de forma muito mais discreta aparece no texto de Kundera em um de seus típicos momentos digressivos. Levantando uma hipótese tão plausível quanto indemonstrável, o romancista tcheco discorre sobre a noção de episódio:

O episódio é uma noção importante da Poética de Aristóteles. Aristóteles não gosta do episódio. De todos os acontecimentos, segundo ele, os piores (do ponto de vista da poesia) são os acontecimentos episódicos. Não sendo uma consequência necessária daquilo que o precede e não produzindo nenhum efeito, o episódio encontra-se fora do encadeamento causal que é a história. Como se fosse um acaso estéril, ele pode ser omitido sem que o relato se torne incompreensível; não deixa o menor traço na vida dos personagens. (...) A vida é assim cheia de episódios quanto um colchão é feito de crinas, mas o poeta (segundo Aristóteles) não é um colchoeiro e deve afastar de seu relato todos os recheios apesar da vida real ser talvez composta apenas desses recheios. (KUNDERA, 1998, p. 297)

Talvez a própria vida seja uma torrente de episódios que a narração organiza e, ao organizar, dota de um sentido propriamente humano. Talvez as personalidades compostas por subtração, operando com um mínimo de mesmidade não ofereça matéria-prima para narrativas identitárias que tenham a forma de grandes romances autobiográficos mas de coleções de contos cuja unidade não se daria pelo enredo e pela ação mas, talvez, pela recorrência dos mesmos temas ${ }^{12}$.

Nossa caminhada com esses dois autores se aproxima do fim. E embora não seja necessário fazer com que Ricoeur preste contas enquanto filósofo, a caracterização do difuso discurso de Kundera permite que aproximemos os dois autores uma última vez, na medida em que enquanto ensaísta e observador privilegiado da história do romance, Kundera não se furta em confiar na arte que pratica e com Ernesto Sabato afirma que "no mundo moderno, abandonado pela filosofia, fracionado por centenas de especializações científicas, o romance nos resta como o último observatório do qual se pode abraçar a vida

12 Desenvolvi recentemente essa hipótese em texto intitulado Qual é o gênero narrativo da vida? Da ilusão biográfica à coleção de contos através da hermenêutica do si (COSTA, 2020b). 
humana como um todo" (KUNDERA, 2006, p. 80). Depois de afirmar que Musil e Broch - seus mestres - já haviam pensado o mesmo cinquenta anos antes, parece legítimo encerrar esse percurso com considerações, digamos, quase apocalípticas de Ricoeur e Kundera.

\section{SERÁ O FIM DO ROMANCE? SERÁ O FIM DA NARRAÇÃO EM GERAL?}

Por razões internas e externas às próprias práticas, parece legítimo, à guisa de conclusão, falar da possibilidade da época ou do momento do fim da narração e em específico da narração romanesca. Ao menos é a convicção de nossos autores.

Kundera afirma que o romance não vai acabar: ele já acabou em vários locais onde se tornou impossível pela força de ideologias antipáticas à sua sabedoria específica. Ricoeur vai mais além, porém, e teme que existam razões internas para que acreditemos que não apenas o romance, mas toda a cultura da narração - a saber, a única que conhecemos - está em vias de desaparecer. De forma notadamente melancólica, Ricoeur reflete, com Benjamin, acerca da possibilidade do fim da arte romanesca. Mencionando Benjamin, diz o filósofo:

"Talvez estejamos no final de uma era em que narrar não tem mais lugar porque, dizia ele, os homens não têm mais experiência para partilhar. E via no reino da informação publicitária o sinal desse retirar-se sem volta da narrativa." (RICOEUR, 2010b, p. 49)

Kundera - que segundo Georges Minois passa a mirar sua ironia na cultura midiática ocidental após ter disparado contra o autoritarismo soviético ${ }^{13}$ - não discordaria, nesse ponto, de Ricoeur. Ao menos é perfeitamente possível perceber em seu romance $A$ imortalidade um ataque feroz, mas matizado de ironia, da mentalidade moldada pela linguagem publicitária que tenta permanentemente tornar 0 mais simplória possível a existência daqueles que estão sob seu jugo. Nem mesmo o pensamento político e filosófico escaparia dessa famigerada lógica:

Há mais ou menos cem anos, na Rússia, os marxistas perseguidos formaram pequenos círculos clandestinos em que se estudava em conjunto o Manifesto de Marx; simplificaram o conteúdo dessa ideologia para difundi-la em outros círculos cujos membros, simplificando por sua vez essa simplificação do simples, a transmitiram e propagaram até o momento em que o marxismo, conhecido e poderoso em todo o planeta, viu-se reduzido a uma coleção de seis ou sete slogans tão precariamente ligados entre si, que dificilmente podemos considerá-lo como ideologia. (KUNDERA, 1998, p. 115)

E se os slogans são a morte ocidental do pensamento lento e complexo do romance, no qual o juízo moral está sempre suspenso e a escuta da sabedoria trágica se possibilita, Kundera também é uma 13 "O riso teria mais futuro voltando-se contra os valores atuais? Milan Kundera explorou esta via: depois de ter rido da burocracia comunista, ele ri da idiotia da cultura midiática ocidental. Mas o alvo desloca-se a todo instante. Os valores antigos, bem definidos e sólidos como uma rocha, determinavam uma franca derrisão, compreendida por todos e por longo tempo. Eis-nos agora no reino do efêmero, cuja moda é a porta-bandeira. A zombaria será tão volátil quanto seus objetos. As dificuldades da arte cômica são evidentes: os grandes cômicos são tão raros quanto os grandes filósofos." (MINOIS, 2003, p. 621-622) 
voz no sentido de que a política e a ideologia podem constituir atmosfera impermeável para a sabedoria romanesca. Tendo afirmado que viu e viveu a morte do romance em ambientes refratários ao discurso romanesco (1988, p. 17-19), Kundera dá testemunho de conhecer e admite temer o estabelecimento definitivo do "dia em que Panurgo deixará de fazer rir" (2009, p. 40-42), isto é, o dia em que de leste a oeste o mundo esteja tomado por uma atmosfera espiritual na qual o desejo de julgar tenha obliterado o de compreender e onde a sabedoria da incerteza que ri da "relatividade essencial das coisas humanas" (1988, p. 13) não terá mais direito de moradia em qualquer parte. A própria ideia de uma sabedoria da incerteza é algo que, segundo Jean Greisch (2013), aproxima enormemente as perspectivas de Ricoeur e Kundera. Para o autor, tanto a arte do romance quanto a hermenêutica são perspectivas nas quais as questões se reabrem e através das quais a dúvida realiza um jogo mais fecundo do que, por exemplo, o do ceticismo filosófico. A ironia romanesca e os jogos imaginativos oportunizados pelo romance, em sua história de exploração de possibilidades humanas, tornam a incerteza uma produtiva fonte de reflexões que, como vimos, Kundera considera que a filosofia frequentemente negligenciou, se arvorando em certezas cujo caráter provisório e revisável foi frequentemente escamoteado.

As reflexões de tom apocalíptico de Kundera parecem encontrar eco nas de Ricoeur, em Tempo e narrativa. Ainda inspirado por Benjamin, Ricoeur vê no colapso da arte específica do romance um sinal do colapso da narração mesma como operação essencialmente humana e sem a qual se torna problemático mesmo pensar a humanidade do humano ${ }^{14}$. Citamos uma passagem longa, mas emblemática, que encerra uma das seções da terceira parte (segundo tomo) de Tempo e narrativa:

Talvez, efetivamente, sejamos as testemunhas - e os artesãos - de uma certa morte, a morte da arte de contar, de onde procede a arte de narrar em todas as suas formas. Talvez o romance também esteja morrendo como narração. Nada, efetivamente, permite excluir que a experiência cumulativa que, pelo menos no campo cultural do Ocidente, ofereceu um estilo histórico identificável, esteja hoje ferida de morte. Os paradigmas de que se falou anteriormente também não passam de depósitos sedimentados da tradição. Nada exclui, pois, que a metamorfose da intriga encontre em algum lugar um limite para além do qual não se poderá mais reconhecer o princípio formal de configuração temporal que faz da história narrada uma história una e completa. E contudo... E contudo. Talvez seja necessário, apesar de tudo, confiar na demanda de concordância que estrutura ainda hoje a expectativa dos leitores e acreditar que novas formas narrativas, que ainda não sabemos nomear, e que já estão nascendo, irão atestar que a função narrativa pode se metamorfosear, mas não morrer. Pois não temos a menor ideia do que seria uma cultura em que não se soubesse mais o que significa narrar. (RICOEUR, 2010b, p. 49-50)

14 Sobre essa convicta mas temerária vinculação entre humanidade e narração, Galen Strawson dispara em Agains Narrativity (2004). Descontente com a vinculação da forma como ela é assumida por autores como Paul Ricoeur, Charles Taylor, Alasdair MacIntyre e Oliver Sacks, Strawson tenta criar um espaço antropológico que admita a configuração de personalidades "episódicas", isto é, que possam ser entendidas como humanas sem o recurso a ideia de história de vida como sendo necessária para a atribuição de humanidade ao indivíduo. Strawson entende essa vinculação entre humanidade e narração como sendo não apenas falsa, mas perniciosa do ponto de vista moral ao excluir do escopo dos humanos aquelas pessoas que não têm interesse ou possibilidade em narrar a si mesmas. 
Convicto de que "a busca de concordância faz parte das pressuposições incontestáveis do discurso e da comunicação" (2010b, p. 48), Ricoeur não deixa de expressar esperança na possibilidade de uma genuína e até então impensável novidade no campo da narração e de suas práticas para além daquela que está dada em seu espaço de experiência ${ }^{15}$. Como uma espécie de âmbito transcendental que se evidencia por sua inegociável operacionalidade a despeito de seu estatuto ontológico, a inteligência narrativa é a única capaz de articular um comércio fecundo entre a discordância da experiência do tempo e a concordância possível no âmbito discursivo. O que está em jogo, para Ricoeur, é um traço antropológico constitutivo da condição humana como tal, e não meramente uma configuração histórica do discurso de um tipo ou outro.

O panorama ricoeuriano é mais amplo e permite que as impressões de Kundera sejam nele alocadas. Se Ricoeur teme a dissolução desse transcendental prático e operacional que é a narração, Kundera localiza sua preocupação de modo mais cronológico e se refere mais especificamente às ameaças que o romance tem de enfrentar. Filho dos Tempos Modernos e construído sobre a herança de Cervantes, o romance é uma prática que só surge na modernidade e em permanente tensão com esse tempo caracterizado pela aurora de um desejo de progresso técnico e material, certamente, mas também de progresso espiritual e humano. Segundo Kundera, porém, o campo científico sempre foi visto como o observatório privilegiado desse progresso que, chegando em seus "paradoxos terminais", pode ser acusado - como o foi por Heidegger e Husserl - de ter esquecido "o ser" e o "mundo da vida" (KUNDERA, 1988, p. 9). Esse privilégio do campo científico como observatório por excelência do espírito do ocidente e do progresso eclipsou a sabedoria expressa numa prática onde o mundo cotidiano jamais foi esquecido: o romance.

Para Kundera, como já sugerimos, não são as estruturas internas da narração nem as combinações e reconfigurações dessas estruturas que ameaçam a narração em sua modalidade romanesca, pois o romance, imbricado com a modernidade, é uma prática narrativa específica e que parece ter sua vitalidade imbricada com a modernidade histórica. Assim, sem a esperança ricoeuriana, Kundera silencia sobre os destinos do romance em "um mundo que não é mais o seu" e sugere, em um ensaio no qual ele mesmo reivindica filiação à "herança depreciada de Cervantes" (1988, p. 23) que se o romance quer progredir como prática terá de fazê-lo "contra o progresso do mundo" (1988, p. 22).

Nós também não podemos tecer profecias sobre o futuro, seja o futuro do romance ou da narração em geral. O que é possível afirmar, desde já, é que não são poucas as vozes que advertem, em forma de prosa ou teoria, acerca da fragilidade de nossas práticas, em nível estruturado e estruturante, diante das razões internas e externas que se gestaram e que as gestaram. Kundera no caso específico do romance e Ricoeur no âmbito da narração em geral nos oferecem um relicário conceitual que nos permite compreender os núcleos e os entornos de nossas crises, no âmbito discursivo, reflexivo e expressivo. $\mathrm{E}$ se a esperança ou falta dela os distancia, a inteligência de suas reflexões certamente pode servir de

15 Sirvo-me aqui do recurso que Ricoeur faz ao pensamento de Reinhart Koselleck, no final de Tempo e Narrativa, quando o filósofo recorre aos conceitos de teoria da história da qual o historiador lança mão para descrever duas estruturas que organizam nossa experiência da história, a saber, "espaço de experiência" e "horizonte de expectativa". Como uma alternativa à totalização dialética do pensamento de inspiração hegeliana, os conceitos de Koselleck aparecem para Ricoeur no momento em que o francês precisa pensar a história de modo que esta guarde alguma autonomia diante da possibilidade de a história ser arregimentada por uma racionalidade avassaladora que faça da história um campo de mera ilustração dessa racionalidade. 
inspiração e permanente lembrança acerca do caráter essencial do que pode estar, silenciosamente, em seu ocaso definitivo.

\section{CONSIDERAÇÕES FINAIS}

Tanto a prática romanesca baseada em uma prosa meditativa quanto sua prática de ensaísta fazem de Kundera um autor privilegiado nos termos das interfaces possíveis com a filosofia - especialmente com aquelas de cariz fenomenológico, hermenêutico e existencialista. Sua visão da pequenez do indivíduo e da estreiteza de sua singularidade tensiona o conceito de identidade narrativa de Paul Ricoeur. Porém, como afirma Trevor Merrill, "ainda que resistam ao imperativo da story, os romances de Kundera ainda contam histórias; ainda que evite a psicologização, seus personagens ainda têm motivações e traços individuais" (MERRILL, 2016, p. 238). Se Kundera inova e compõe de maneira criativa, ainda é na esteira de uma tradição que se constitui no próprio jogo da inovação e da sedimentação - jogo que dá a observar, segundo Ricoeur, uma história de metamorfoses da intriga. No limite, ainda que enquanto pensador Kundera exorte composição da identidade por subtração de traços, esse modelo identitário ainda permanece concebível, descritível e narrável, na hermenêutica do si ou no romance meditativo.

\section{REFERÊNCIAS}

BARROSO-FILHO, Wilton. A voz filosófica do narrador kunderiano. XI Congresso Internacional da ABRALIC: Tessituras, Interações, Convergências. 13 a 17 de julho de 2008. USP - São Paulo, Brasil.

BOTTON, João Batista. 0 homem como promessa: estudo das implicações da antropologia filosófica de P. Ricoeur. Belo Horizonte, 2017. Tese (Doutorado em Filosofia). Pós-graduação em Filosofia da UFMG, 2017. COSTA, Vítor Hugo dos Reis. Autenticidade e alívio: Kundera além de Sartre. Guarapuava, PR: Revista Guairacá (Unicentro), 2012.

COSTA, Vítor Hugo dos Reis. Para morrer é necessário ser alguém: a ipseidade mínima de Meursault diante do desafio romanesco. Revista Mímesis, v. 41, n. 2. Centro Universitário Sagrado Coração - Bauru São Paulo, 2020.

COSTA, Vítor Hugo dos Reis. Qual é o gênero narrativo da vida? Da ilusão biográfica à coleção de contos através da hermenêutica do si. Em: TIELLET, Claudia; CARRÉ, Douglas (Orgs.) Ricœur em perspectivas [recurso eletrônico] / - Porto Alegre, RS: Editora Fi, 2020.

COSTA, Vítor Hugo dos Reis. 0 romance como expediente hermenêutico: sobre a historicidade e a singularidade do existente humano. Guairacá Revista de Filosofia, Guarapuava-PR, v. 36, n. 1, 2020.

GENTIL, Hélio Salles. Filosofia e literatura: apontamentos sobre o romance. Limiar - v. 3, n. 5 - $1^{\circ}$ semestre de 2016.

GREISCH, Jean. Paul Ricoeur: la sagesse de incertitude. Argument: Biannual Philosophical Journal 3 (2):475-490, 2013. 
KUNDERA, Milan. A arte do romance: (ensaio). Tradução de Teresa Bulhões C. da Fonseca e Ver Mourão Rio de Janeiro: Nova Fronteira, 1988.

KUNDERA, Milan. A cortina: ensaio em sete partes. Tradução Teresa Bulhões Carvalho da Fonseca - São Paulo: Companhia das Letras, 2006.

KUNDERA, Milan. A imortalidade. Tradução de Teresa Bulhões Carvalho da Fonseca e Anna Lucia Moojen de Andrada. São Paulo: Círculo do Livro, 1998.

KUNDERA, Milan. Los testamentos traicionados. Traducido por Beatriz de Moura - 1. ed. 1. reimp. Buenos Aires: Tusquets Editores, 2009.

MACINTYRE, Alasdair. Depois da Virtude. Trad. Jussara. Simões. Bauru: EDUSC, 2001.

MERRILL, Trevor Cribben. 0 livro da imitação e do desejo: lendo Milan Kundera com René Girard. Tradução de Pedro Sette-Câmara - 1. ed. - São Paulo: É Realizações, 2016.

MINOIS, Georges. A história do riso e do escárnio. Trad. Maria Elena Ortiz Assumpção. São Paulo: Unesp, 2003

RICOEUR, Paul. O si mesmo como outro. Tradução Ivone C. Benedetti. - 1a ed. - São Paulo: Editora WMF Martins Fontes, 2014.

RICOEUR, Paul. Tempo e Narrativa. (Tomo II) Tradução de Márcia Valéria Martinez de Aguiar; introdução de Hélio Salles Gentil. - São Paulo: Editora WWF Martins Fontes, 2010.

RICOEUR, Paul. Tempo e Narrativa. (Tomo III) Tradução de Márcia Valéria Martinez de Aguiar; introdução de Hélio Salles Gentil. - São Paulo: Editora WWF Martins Fontes, 2010.

ROSSATTO, Noeli. Singularidade, narratividade e mundo comum: uma perspectiva fenomenológica. Em: Filosofia e educação: interatividade, singularidade e mundo comum / Amarildo Luiz Trevisan, Noeli Dutra Rossatto, (organizadores).- 1. ed. - Campinas, SP: Mercado das Letras, 2013.

SARTRE, Jean-Paul. A transcendência do ego: esboço de uma descrição fenomenológica. Introdução e notas, Sylvie Le Bon; tradução de João Batista Kreuch. - Petrópolis, RJ: Vozes, 2013.

SETYADI, F. Wawan. Novel and refiguring life. International Journal of Humanity Studies. Sanata Dharma University, Yogyakarta, Indonesia. Vol. 2, No. 2, March 2019.

STRAWSON, Galen. Against narrativity. Ratio 17 (2004): 428-452. 